\title{
Regarding the shipwreck of others: for a critical visual topography of Mediterranean migration
}

\section{Chiara Giubilaro}

University of Milano-Bicocca, Italy

\begin{abstract}
This article reflects on the relationship between photography and migration from a cultural geography perspective, with particular reference to the visual construction of the Mediterranean border regime. The contemporary aesthetics of Mediterranean migration is one of the domains in which visual and social norms are most closely intertwined. My main purpose is to unveil these processes of mutual (re)production by analysing how photographs forge our everyday perceptions of migration and affect our very ability to produce ethical and political responses to the events they portray. Drawing on a range of fields and approaches, including cultural geography, visual culture studies and postcolonial theories, I attempt here to develop a critical topography of looking, mapping out some of the performances and places involved in looking at Mediterranean migration. In the final part of the article, I seek to reinforce my theoretical statements by focusing on two photographic images of people being rescued along the Mediterranean route, in order to illustrate how photography can actually interfere with our ability to create spaces of cultural and political responsibility.
\end{abstract}

\section{Keywords}

Mediterranean, migration, photography, topography of looking, visual geography

\section{Introduction}

On 6 November 2015, Greek photographer Aris Messinis posted an emotional account of his experience working on Lesvos to the Agence France-Presse Correspondent blog. In an attempt to convey the sense of panic and defeat enveloping the island during the so-called European refugee crisis, he wrote:

The most shocking thing for me about covering this story is that you constantly realize that you're not in a warzone. [ . . . It's also hard because you have to capture the difficulties of these people, and the pain

\section{Corresponding author:}

Chiara Giubilaro, Department of Sociology and Social Research, University of Milano-Bicocca, Via Bicocca degli Arcimboldi 8, 20126 Milano, Italy.

Emails: chiara.giubilaro@unimib.it; chiaragiubilaro@gmail.com 
of these people, but it's not dangerous for you. When you're at a war, there are dangers for you, too, so somehow, you're on a more equal footing with the people you're covering. But here, there are no dangers for you. ${ }^{1}$

The Greek island of Lesvos is just one of the dramatic stages on which the contemporary border spectacle plays out. ${ }^{2}$ Since at least 1992, EU migration policies have been transforming the Mediterranean Sea into a liquid space of deadly journeys and vulnerable bodies, where geopolitics combines with neo-colonial forms of violence and racism. ${ }^{3}$ Our perceptions of these places and events are constantly mediated by pictures, videos and photo reports, which meet our eyes and influence our emotions, negotiating the distance between us and what is being portrayed. ${ }^{4}$ Indeed, visual language is probably that most pervasively deployed to bring migration into the public domain: images of boats suspended on the surface of the sea, wrecked sea vessels run aground, crowds of bodies on docks, and corpses lying on beaches, have increasingly attracted media attention, gradually building up a visual narrative of contemporary migration across the Mediterranean Sea.

In this article, I set out to critically exploring the relationship between photography and migration from a cultural geography perspective. Transferring Cindi Katz's notion of topography to the visual field, ${ }^{5}$ I attempt to develop a critical topography of looking, ${ }^{6}$ mapping out the multiple performances and places involved in looking at migration through a photographic lens or image. As we shall see, the distinct aim of this topography is to identify and examine the connections among the geographically distant places where the distinct material processes of picture-taking, editing and seeing are enacted. Although the role of (in)visibility in the production and management of border regimes has been widely debated among geographers and social scientists, ${ }^{7}$ the visual representation of contemporary migration remains somewhat underengaged, especially its performative and material aspects. This is because most existing studies on the relationship between visual images and migratory events adopt a content analysis methodology, focusing almost exclusively on what is portrayed inside the frame in terms of composition, focus, spatial organization, expressive content and so on. ${ }^{8}$ My key argument in this article is that the significance of the visual does not reside exclusively at the site of an image, but also in the constellation of events of place ${ }^{9}$ that continuously perform the image's production and reception.

In support of this argument, I first outline a transdisciplinary framework privileging the strategic opportunities that reading images from a cultural geography perspective may bring to light. Rather than simply exploring photography by analysing its visual content, I extend my focus to include the unstable relationship between the image and its viewers, whether the photographer, the spectator, or the researcher. This epistemological shift - from visual content to visual event - points my inquiry towards the intertwining of subjects, spaces, and pictures in which every visual performance is unavoidably enmeshed.

The contemporary aesthetics of migration is one of the domains in which visual and social norms are most closely intertwined. Although the role of media in shaping our imagery of migrations has sparked renewed interest among scholars - particularly over the last two decades - the field of photography has received little dedicated attention, as reflected in its omission from a 2001 volume edited by Russell King and Nancy Wood, Media and Migration. ${ }^{10}$ In the second section of this article, I set out to reintroduce photography as a focus of analysis for exploring the cultural politics of migration, going on to examine how aesthetic, emotional, and political dimensions overlap in any visual performance.

In the final part of the article, I seek to reinforce my theoretical statements by focusing on two photographic images of people being rescued along the Mediterranean route. Although I take the visual content as the starting point for my analysis, I also home in on what is happening outside of the visual frame, in the spatial interweaving of images, gazes, and aesthetic regimes that governs 
both the production and reception of such photographs. This leads me to raise critical questions, such as where, when, and under what conditions does the photographer relate with his subjects? How is the framing process made possible? What kind of space is produced by the acts of capturing and looking at these images and, above all, how are our gazes emotionally and politically affected by such visual performances? In assessing these questions, I analyse the photographs using a mixed methodology that includes critical visual discourse analysis and in-depth interviews with the photographers. ${ }^{11}$ I suggest that such a methodology is crucial if we are to tease out - at least in part the cultural and social implications of visual performances.

As visual culture scholars have persuasively argued, ${ }^{12}$ images are invariably a matter of acts and performances. Here, I posit that exploring visual events from a cultural geography perspective can shed light on the relational and spatial practices to which photography continuously gives rise. In this sense, producing a topography of looking means rethinking photography as an assemblage of visual places where multiply situated gazes intersect and produce political, emotional and cultural outcomes. If the challenges raised by photography are to be addressed, we require the input of geographers to explore the shifting and transformative field in which images, subjects, and spaces relate to one another. Mapping this uncertain terrain is the main task I set out to accomplish in this article.

\section{Topographies of looking: from visual content to visual event}

Photography has been attracting the attention of geographers since its invention. ${ }^{13}$ Although its popularity within the discipline cannot be compared with that of other visual media, such as cartography and film, some scholars have recognized its importance as both an instrument and an object of geographical knowledge. ${ }^{14}$ In his account of the relationship between geography and the media, Paul Adams has defined photography as an 'enigmatic space of encounter'. ${ }^{15}$ Its seemingly ordinary surface, he argued, conceals a deep space in which materiality and immateriality, visual objects and affective relations, blend together. The increasing pervasiveness and supposed transparency of this 'banal medium' ${ }^{16}$ poses specific challenges for cultural geographers, in terms of both their theoretical speculation and their research practice. As Gillian Rose has brilliantly pointed out in her work on geography and the visual, images should be seen as spaces of differential relations, ${ }^{17}$ in which multiple gazes and events intersect and overlap. Visual objects, observant subjects and exhibition spaces interact according to peculiar and shifting patterns of signification. Hence, if we truly wish to engage with the questions of power implied in any visual performance, we need to extend our analysis from the mere photographic surface to the affective spaces of our encounter with it. ${ }^{18}$ It is precisely in the shift from representation to relation that a topographic approach to photography, with its specific conceptual and methodological implications, becomes of value.

For we are now exploring a space of performance and encounter that is 'an assemblage of signification, material objects, affects, multisensory elements and context'. ${ }^{19}$ With each viewing, the photograph performs different effects on its spectators, shaping specific perceptions about the people, events and places portrayed on its surface. To echo Sontag's words, not only is picture-taking an event in itself, ${ }^{20}$ but so is picture-seeing. In other words, each time a gaze is brought to bear on a photograph, effects and affects will follow. None of these events can be separated from the material spaces of their happening. To transpose a concept developed by Massey to the visual domain, I suggest defining such performances as visual events of place, the 'here' and 'now' of the relationship between an observing subject and an image, a constellation of multiple and open-ended processes rather than a thing. This means acknowledging that photography is not just a matter of pictures and frames, but rather involves bodies, gazes, spaces and the contingencies of their 'throwntogetherness'. ${ }^{21}$ Indeed, the purpose of a topography of looking is to identify a set of visual events of place performed by a given photograph and critically 
examine the connections among them in relation to specific practices of looking. Extending the theorizing of Katz to the realm of visuality, we may reconceptualize photography as the product of a translocal assemblage of distinct and distant performances, whereby the visual content itself is just one of the locations we need to take into account. The beach on the Turkish coast where the photographer encounters her subject, the newsroom where her photographs are edited and distributed, the millions of screens viewed by a multitude of spectators across the world, and the study in which a group of researchers analyses both the photographs and the associated imagery 22 are some of the visual events of place a topography of looking needs to include among its contour lines. Hence, exploring photography from a topographic perspective implies attempting to grasp some of the challenges animating the visual field and in so doing to fully recognize its performative and relational dimension. The goal here is twofold: on the one hand, to explore the complex spatialities where images, gazes and objects intersect and on the other hand, to situate photographs in their broader context by examining the (dis)connections among the different visual events of place they enable. As we shall see, drawing on topography as a distinct form of inquiry within the field of visual culture can allow us to expand our understanding of photography by exploiting the rich potential inherent in approaching images from a distinctively geographical perspective, both epistemologically and methodologically.

Such a shift in emphasis from visual content to visual event has concrete implications for how we analyse photography, raising specific methodological challenges. In particular, as Gillian Rose has compellingly pointed out, while content analysis sheds some light on the intersections between visual codes and power regimes, it can fail to fully capture the complexity of this kind of visual performance for at least two reasons. ${ }^{23}$ First, in assigning a single meaning to specific visual content, it assumes that different spectators in different spaces see the same image in the same way, tacitly implying the existence of a universal spectator. ${ }^{24}$ Thus, not only is the plurality of subjects largely overlooked, but more significantly the role and positioning of the researcher is neglected. If visual meanings can be established as fixed and unambiguous, then we lack a framework to account for the intrinsically shifting relationship between images and the researcher looking at them. ${ }^{25}$ The second risk is closely related to the first, and confirms the urgent need for a geographical approach to photography. By exclusively focusing on what is portrayed inside the visual frame, content analysis ignores both the space of its production and the space of its audiencing. ${ }^{26}$ Hence, questions related, for example, to the role of the photographer, the patrons who commissioned his or her work, funding and publishing processes, the dissemination of the photograph, or its different circuits and audiences, are essentially excluded from the field of inquiry. If we wish to grasp such complex visual economies ${ }^{27}$ and the geographies underpinning them, we need to decentre our understanding of photography from its visual content. Photographs produce, or rather co-produce, deep spaces imbued with affective intensities, power relations and cultural meanings. It follows that not only do we require a 'History of Looking', as called for by Roland Barthes in his seminal work on photography, ${ }^{28}$ but also more significantly for our argument, we need a topography of looking, a critical account of the embodied, relational, and shifting events of place that a photograph performs. Clearly, it is far from my intention to completely dismiss content analysis methodologies. Rather, I argue that although visual content is an indispensable starting point for the analysis of photography, we should also engage with the material processes involved in its production and audiencing. As Elizabeth Edwards has argued, 'Approaching photographs from a spatial perspective [ . . ] perhaps goes some way to moving photographs away from their essentializing tendencies'. ${ }^{29}$ Furthermore, reconceptualizing photography from a cultural geography perspective gives us considerable theoretical and practical access to its shifting meaning, which in turn provides the potential for a reflexive approach to visual events of place. 


\section{(Un-)framing migrations: borders on stage}

The issue of migration and its visual representations have become the focus of growing interest over the past decade. Indeed, the spread of photographic exhibitions and art projects on migrants and migrations across Europe, the impressive number of prizes and awards assigned to photographers working along the migration routes by prestigious photo contests, such as World Press Photo, Pulitzer and Visa d'Ors, and of course, the dramatic rise in academic lectures, conferences and publications on borders and media representations/visual performances, all play a crucial role in the cultural and discursive construction of contemporary migration.

This proliferation of images portraying the so-called 'European migrant crisis' calls for greater reflection on its social and cultural implications. While a rich field of research has sprung up at the intersection between migration studies and cultural studies, especially over the last two decades, ${ }^{30}$ the role of photography has been often overlooked or underestimated compared to that of other media such as film, music and literature. We are incessantly exposed to often-dramatic photographs of shipwrecks, landings and detentions framing the routes of those who choose to leave their country in search of alternative lives and possibilities. Nevertheless, the multiple potentialities of photography to shape our individual or collective perceptions of migration, and its different entanglements with social, economic and political contexts, still need to be addressed. Indeed, as earlier stated, scholarship on visual media and contemporary migrations has largely been dominated by visual content analyses. ${ }^{31}$ This methodology, at first glance, may appear to be particularly appropriate for scrutinizing visual representations of migratory events. Anonymous masses of black men, threatening boats approaching our coastlines, and exhausted women in need of our help and pity, are examples of the most recurrent visual stereotypes portraying Mediterranean migration in the mainstream European media. Such highly standardized visual patterns have encouraged the widespread use of content analysis, which focuses on interpretations of the image itself in order to relate visual elements to broader social and cultural meanings, especially dehumanizing and objectifying strategies for framing non-white others. ${ }^{32}$ As argued in the previous section, despite the undeniable importance of this approach in analysing migration photography, it fails to adequately access the intricate network of embodied, relational and affective events of place that photography performs.

Before analysing how migratory events are framed and how these frames interfere with our emotional and political dispositions, I would like to define the theoretical grounds for this line of inquiry. When investigating migration photography, there are at least three intersecting fields of study that need to be taken into account and leveraged in support of our critical inquiry. I view each of these as a specific key polar dimension, whose meaning relies on its connection with or disconnection from the others. The first dimension that migration photography brings into play is aesthetics, by which I understand the entire set of objects, technologies and practices that contribute to making up a visual event. Far from being exclusively a matter of vision, aesthetics concerns 'an experience of sensate binding', ${ }^{33}$ an encounter based on the senses that invariably generates a plural and open experience. Any aesthetic event always implies a dynamic, embodied and socially produced relation between the observer and the observed, a process where the gaze is literally caught up in the attraction of the visual object. Images gain their power through sensation and interaction: they have an active capacity to affect, move and transform us in contingent and unpredictable ways. This aesthetic force adds a relevant, albeit challenging, dimension to the interpretive agenda of visual culture studies and its German correlate Bildwissenschaft. ${ }^{34}$ In particular, Mitchell ${ }^{35}$ and Bredekamp ${ }^{36}$ emphasize the performative dimension of the visual, focusing on the importance of examining what pictures do, rather than what they represent. Crary concentrates on the cultural histories of our ways of looking at images, redefining the observing subject as 'both 
the historical product and the site of certain practices, techniques, institutions, and procedures of subjectification' ${ }^{37}$ Turning more specifically to photography and its visual grammar, the seminal works of Roland Barthes, ${ }^{38}$ Susan Sontag ${ }^{39}$ and John Berger ${ }^{40}$ allow us to move beneath the mere surface of the photograph to plumb the depths of its 'profound madness', ${ }^{41}$ recognizing its active power to shape imaginaries, provoke emotional responses, and elicit political engagement.

Indeed, the political is the second key domain in my visual analysis. While the relationship between visual practices and power regimes has been explored across several disciplines, ${ }^{42}$ it is in the work of postcolonial scholars that the fullest understanding of it has been developed. As observed by Stuart Hall, the look is always a site of power-knowledge. ${ }^{43}$ All practices of looking are embedded in specific hierarchies and established hegemonies. ${ }^{44}$ From the disassembling white man's eyes assailing Frantz Fanon ${ }^{45}$ to the terrifying white gazes experienced by bell hooks ${ }^{46}$ and from Diawara's resisting black spectatorship ${ }^{47}$ to the role of visual stereotypes in constructing colonial discourse examined by Bhabha, ${ }^{48}$ postcolonial scholars have long called into question the power geometries of the visual and their dehumanizing effects. No visual event can ever be separated from its political effects. The field of vision is racially saturated and crossed by violent asymmetries that establish silent distinctions between those with the right to see and represent and those who are precluded from doing so. Hence, a critical reading of migration photography cannot evade fundamental questions about the ways in which looking produces not only racialized images, but also - more importantly - racialized viewers. ${ }^{49}$

Third, the visual places I examine in the next section also engage the emotional sphere or, in the words of Sara Ahmed, those 'affective economies of emotions' in which the psychic and the social, the individual and the collective meet. ${ }^{50}$ Images bear the traces of distant bodies and events that can sometimes affect viewers and interfere with their emotional responses. Thus, the gaze can be a site of compassion, desire, indignation, shock, pity, indifference, and so on. The space of encounter enacted by photographs is filled with affective ties, raising questions such as the following: What happens when we look at the images of suffering? How are we emotionally affected by these photographs and what other effects follow from this? And how does our affect relate to our political practices? As we shall see in the following paragraphs, critical scholars from different disciplines have long discussed the emotional valences and implications of this kind of image, particularly in the domain of war photography. ${ }^{51}$ I propose that an analogy may be drawn between migration photography and war photography. This analogy - in my view - is far from arbitrary and bears key conceptual implications we should not overlook. As reflected in the words of photographer Aris Messinis, whom I cited at the opening of this article, what is happening at European borders should really be viewed as low-intensity warfare ${ }^{52}$ and the Mediterranean as a liquid battlefield where a necropolitcal regime ${ }^{53}$ is silently in operation.

In the following section, I attempt to rethink migration photography from this triangular perspective of aesthetics, politics and the emotional. Building on this critical triangulation, my topographical aim here is to analyse specific visual events by focusing on these three dimensions and the questions underlying them. Crucially, I do not set out to merely describe the vertices of the triangle, but rather to explore its sides and connections. In brief, I examine how aesthetic, political and emotional features concretely interact in our performances of looking, seeking to map out the relative tensions, contradictions, synergies and interruptions.

Before proceeding to outline tentative visual topographies of the Mediterranean border, one final caveat; visuality is a field of shifting significations and mobile assemblages. The ways in which aesthetic codes, political regimes and emotional responses combine largely depends on the embodied subject who is looking at the photograph and the 'here' and 'now' of this visual event. Thus, each line of the topography I seek to map out in the next section is inescapably affected by my own perspective as a white Western female scholar. While my analysis of the places of visual 
production and distribution is supported by interview data, I examine the performance of spectatorship through the specific lens of my own perceptual experience. Far from setting out to somehow reaffirm the notion of a universal and homogeneous viewer, I conceive of my own gaze as a site where some of the various risks raised by visual performances may be explored and critically questioned. In examining the site of reception, I focus on the pitfalls that potentially await me in the intimate encounter between my gaze and the photographic image, with implications for the ethical, political and emotional outcomes. Given its situated, embodied and partial nature, this topography cannot therefore provide definitive answers on how photographs contribute to representing border events, but hopefully it can nevertheless raise a set of critical questions about our ways of engaging with and being responsible for these images.

In the following section, I draw on the conceptual premises outlined above to critically analyse two photographs and the visual performances involved in their production and reception. Both of the selected photographs were shot by Italian photographers in the Mediterranean region between 2015 and 2016. Despite their spatial and temporal similarity, they differ considerably with regard to the institutional subjects that commissioned them: the European Border and Coast Guard Agency Frontex and the humanitarian NGO Médecins Sans Frontières (MSF, Doctors Without Borders), respectively.

For the reasons explained earlier, I adopt a mixed methodology that combines visual content and critical discourse analysis. ${ }^{54}$ As a further step towards shedding light on embodied practices of framing borders, I conducted a series of in-depth interviews with professional photographers supplemented with additional web resources.

\section{The embedded gaze}

In November 2014, the European Border and Coast Guard Agency Frontex launched Triton, a joint search and rescue mission in the Central Mediterranean aimed at 'combating people's smuggling networks, trafficking of human beings and other cross-border crimes' ${ }^{55}$ As on earlier occasions, Frontex assigned the task of documenting the operation to the Italian photojournalist Francesco Malavolta, who has been reporting on the situation at Europe's borders since 2011. ${ }^{56}$ Understanding more fully the site of production of these photographs requires attending to the social context in which they were taken, and specifically the role of the photographer and his relationship with European agency Frontex. Malavolta is Frontex's official photographer and his work may be viewed as similar to the embedded reporting practices first implemented during coverage of the British campaign in the Falklands in $1982 .{ }^{57}$ After a trial period of a couple of years, he was officially recruited by Frontex and put in charge of photo documenting events at Europe's external and internal borders, gradually winning the trust of his supervisors and a reasonable degree of autonomy. Italy, Greece, Turkey, Serbia, Hungary and the Mediterranean Sea are some of the stages to which he has been assigned in recent years. After each mission, the photographs shot by Malavolta are acquired by Frontex, who hold all ownership rights for them. By Malavolta's own estimate, Frontex digital archives for the years 2011-2015 include approximately 1 million of his photographs. To date, only a few 100 have been published on the agency's official website or in its reports.

Francesco Malavolta began reporting on migration events during the 1990s, when the Eastern coasts of Italy became the main destination for people fleeing from Albania. Since then, he has never stopped and - he adds - he will not stop as long as people continue to lose their lives while crossing borders. ${ }^{58}$ For Malavolta, documenting border events is an ethical mission, a stance that is reflected in his ongoing engagement with the topic through his Facebook page. His core strategy is to make looking a deeply emotional experience, with a view to raising his audiences' awareness and eliciting reactions: 'I expect the people who look at my photographs to think about these children as if they were their own. It is less a matter of pity than of sympathy'. ${ }^{99}$ When a boat is 


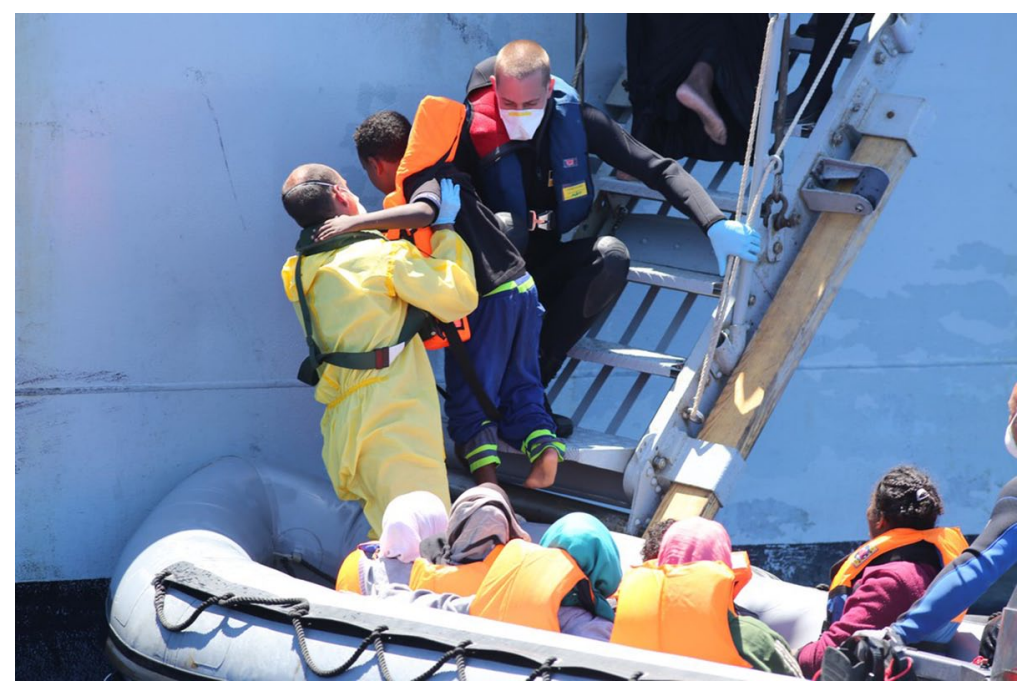

Figure I. Search and rescue operation by the Belgian navy vessel Godetia (as it appears on the Frontex website).

Photograph by Francesco Malavolta (reproduced with the author's permission).

approaching, Malavolta knows that he needs to focus on children, women and older people, for at least two reasons, which are, they cannot be considered a threat to our safety and their vulnerability is somehow touching: 'If I show you a group of strong black men I will not touch your heart as a mom with her child can do'. ${ }^{60}$ In his account of this particular visual place, the emotional and political dimensions are deeply intertwined; triggering sympathy in Malavolta's view is a strategy for increasing political awareness of what is happening at our borders. However, his quest to establish an intimate connection between his photographs and those viewing them stands in contrast with his own mode of encounter with his photographic subjects: 'When I photograph, I tend to become invisible: I am there and I am not' ${ }^{61}$ Choosing to minimize his interaction with his subjects is part of a conscious strategy to remain detached from the people he photographs.

This way of conceptualizing his work and operating in the field profoundly impacts the visual places where Malavolta's camera throws itself into the spectacle of Mediterranean migrations. It was within this discursive and material context that, while on board a patrolling Belgian Navy vessel in the summer of 2015, Malavolta took the first of the photographs in this topography, which was later published on Frontex's official website as part of a photo-gallery on Operation Triton (Figure 1). ${ }^{62}$

There is another place we cannot overlook in our visual topography, namely the ways in which Frontex engages with Malavolta and his work. This is a crucial stage in the production of this topography. Not only does Frontex issue precise guidelines on how the photography work should be executed - including what should fall within the frame and what should not - but it also selects, organizes and distributes the resulting photographic material, according to highly specific visual and social norms. On browsing through the 20 photographs in the gallery, one is immediately struck by the strong similarities among the pictures. Black men are crowded on rubber dinghies or sitting on the deck of a vessel, women and children are preparing to disembark or walking along gangways, while yellow-clad crew members wearing medical masks and protective gloves are supervising and assisting rescue operations, throwing a life jacket, offering glasses of water, or providing medical assistance. The organization of these photographs' visual contents and meanings 
is characterized by a strongly recursive pattern and this aesthetic trait can influence our affective disposition towards them. The basic repetition of schemas, actors, and gestures is somehow reassuring. Nothing disturbs our gaze and each visual detail appears to be in its rightful place; the border spectacle ${ }^{63}$ has been staged with precision.

Thanks to the strategies adopted by Frontex' Press Office, the humanitarian and the securitarian narratives that synergistically contribute to 'borderization processes' ${ }^{64}$ receive solid visual backup. Here, we can easily recognize all the visual clichés in the securitarian register: the constant presence of crew members implies the promise of permanent surveillance; the masks and gloves evoke the perpetual risk of infection; the ordered organization of spaces reflects the need to control and discipline the bodies of those rescued. In parallel with this securitarian narrative, the humanitarian logic is also in operation in these frames. Women and children are the only subjects to be portrayed close up and in small groups. They are carefully framed as vulnerable people who deserve our benevolent care and need our protection to survive. As several scholars have rightly pointed out, ${ }^{65}$ such visual mediations run the risk of victimizing these subjects, depriving them of any possibility of agency. Conversely, this kind of representation may authorize the state 'to gratuitously fashion itself as a paternalistic (indeed, patriarchal) protection racket'. ${ }^{66}$

This aesthetics of securitarian humanitarianism introduces some productive tensions into the triangulated dimensions described in the previous section. When I as a Western, white, female spectator look at the photograph of a child who has just been rescued from an unsafe dinghy or a mother crying on the deck of a rescue vessel, a sense of pity and compassion suddenly pervades my gaze and body. The political implications of this kind of emotional response have long been debated in relation to war photography. Many scholars have argued that a sympathetic disposition towards vulnerable others contributes to establishing an asymmetrical viewing relationship between the suffering bodies in the frame and the observer 'that render foreign spaces as damaged and foreign others as abject in order to secure ourselves as morally concerned and compassionate political agents' ${ }^{67}$ The experience of the subjects we are looking at remains somehow inaccessible. ${ }^{68}$ My emotional response establishes a distance between my safe position and their dangerous one, a desperate asymmetry between here and there ${ }^{69}$ and it is precisely in this impossible distance that the viewer's political engagement fails to obtain.

Although this view is not entirely invalid, I am more interested in drawing attention here to another possible assemblage among humanitarian aesthetics, affective sympathy and political $\mathrm{im} /$ possibilities. In a key work on war photography, which is explicitly evoked in the title of this article, Susan Sontag highlights the risks of sympathy in relation to images of suffering: 'So far as we feel sympathy, we feel we are not accomplices to what caused the suffering. Our sympathy proclaims our innocence as well as our impotence'. ${ }^{70}$ The risk here is not the emotional distance between the subjects in the photograph and me looking at them, but rather an excess of proximity. When we engage with images of suffering, we tend to suppress the historical, geographical, and political distance that exists between us and the objects of our compassion: we thereby dissolve both the singularity of their experience and the burden of our own position, transforming pain into a universal condition. Thus, maintaining a certain level of critical detachment from our compassion can help us to more effectively recognize our political and ethical responsibility for the events portrayed and the suffering that such events continue to provoke in the present.

The aesthetics of humanitarianism, by governing my emotional responses and thus compromising my capacity to enter into ethical relationships, reduces the spaces available to me for political action. The child escorted on the Belgian Navy's vessel does not outrage or chill me. Before this photograph, we risk perceiving ourselves as impotent and innocent witnesses to the ineluctable making of history. 


\section{The humanitarian gaze}

On 16 August 2015, Italian photographer Francesco Zizola embarked on the Bourbon Argos, a vessel run by the humanitarian NGO MSF, setting out to conduct search and rescue operations off the coast of Libya. Some months earlier, President Loris De Filippi had announced MSF's decision to launch sea operations in partnership with MOAS (Migrant Offshore Aid Station), in response to the large-scale humanitarian crisis generated by European policies post-Operation Mare Nostrum. ${ }^{71}$ The choice to involve a professional photojournalist in the mission reflects the leading role of visual communication within MSF's policy of témoignage (bearing witness), as expressly stated in its photographers' sensitization document: 'they [pictures] can demonstrate reality, expose neglect and despair, inspire hope and understanding, and connect people around the world. They can also help MSF raise money to continue our work and inspire people to come and work with us'. ${ }^{72}$ Photo-documentation is a key dimension of MSF's communication strategy; it is shaped by a complex assemblage of economic, political and cultural factors that we cannot overlook in analysing the relations among the multiply situated social actors in our visual topography.

This is the institutional framework within which Zizola's work needs to be investigated. During the photographer's 3-week stay on the Bourbon Argos, over 3,000 people were rescued, along one of the deadliest migratory routes in the world. Shortly afterwards, Zizola decided to translate his experience aboard the Bourbon Argos into a photograph collection, also making a short video that combined images, text and a soundtrack. In the same boat is the title of both these works. ${ }^{73}$ When asked about the aim of this project, Zizola explained that it was an effort to resist and subvert the emphasis on anonymous masses and numbers in mainstream representations of migrants at sea:

I tried to lend stature to their humanity by showing their gazes, expectations, fears, as they were there in

front of me. It was an attempt to move in closer and establish a proximity between these human beings and our lives, in order to persuade the public to change their shallow and cynical views on this issue. ${ }^{74}$

The place where Zizola met his subjects and captured their experience, in this case on the deck of the Bourbon Argos, was produced through a delicately negotiated trade-off between interaction and respect, with his striving for proximity becoming a conscious strategy of associating an aesthetic regime with a political goal. In Zizola's view, photography can turn looking into a space for active engagement and the humanization of experience.

In December of the same year, an image from the series was ranked one of the best photographs of 2015 by the Guardian and a few months later, the entire reportage won second prize in the 'Contemporary Issues - Stories' section of the World Press Photo 2016 edition. The most successful photograph of the collection shows a group of men wrapped in emergency blankets intently looking into the distance while, as Zizola commented in an interview, ${ }^{75}$ the outline of the Southern European coast was just coming into view (Figure 2).

Shifting our attention once more to the place of spectatorship and its potential traps, this second photograph raises the question of possible dis/connections between the aesthetic, the ethical and the political. Of course, as previously argued, the following reflections do not represent a thorough account of the endless possibilities that looking at this photograph can open up. However, I strongly believe that focusing on my own performances of looking and the risks associated with them can offer a useful prism through which to explore how images interrogate our gaze and positioning in relation to the events portrayed in them.

In an interview with the Italian magazine Sguardi, Francesco Zizola explained his stylistic choice of black-and-white photography: 


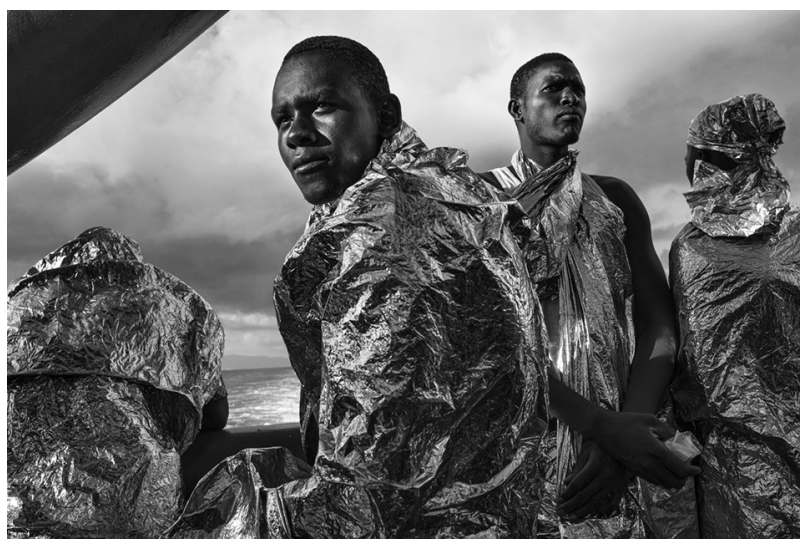

Figure 2. In the same boat - search and rescue operation by Médecins Sans Frontières off the Libyan coast.

Photograph by @ Francesco Zizola / NOOR (reproduced with the author's permission).

Through my photographs I try to narrate reality, which is the first degree of representation, but then I try to make sure that this first degree contains a second one, which I refer to as symbolic. Black and white helps the reader to look out for this second degree of representation. ${ }^{76}$

Before this black-and-white, high-contrast photograph, my perception of what is portrayed is transported into a symbolical realm, where historical events blur into a mythical story and real bodies seem like crystallized icons. Significantly for the purposes of my argument here, the viewer's gaze is invited to identify a symbolic and eternal principle in the frame. When I look at the two men staring towards the horizon, the historical and spatial 'thereness' of the photograph ${ }^{77}$ is transcended, its temporality expanded. The symbolic overrides reality, and my gaze is propelled outside of time and space. This particular aesthetics and its de-historicizing force raise critical questions with a bearing on the political dimension, because they jeopardize my capacity to open up a space of engagement and agency. When an event is symbolized and emptied of its historicity, it follows that its outcomes appear to be ineluctable. The men we are now observing, their fierce look and posture, are trapped in an ahistorical and aspatial dimension. Their rescue becomes a symbol of all possible rescues. This scene has been, is, and always will be. Its aesthetic force drags the image and me as a viewer outside of history and transformative processes, to a place where nothing can ever really change. This is the risk of de-politicization that eternal images can often bear. ${ }^{78}$

Another possible risk of this kind of aesthetics which is widespread in both migration and war photojournalism is what we might call the aestheticizing trap. Images of war and violence are often marked by a search for beauty: balanced compositions, infallible symmetries, high contrasts, artistic visual quotes and so on, 'dress up' dramatic events with a seductive iconography. As many scholars have observed, this aestheticizing tendency carries broader political implications that deserve more careful consideration. ${ }^{79}$ The key point to be emphasized for the purposes of our argument here is that looking at these beautiful yet terrible photographs somehow reinforces my passive role as observer. The relationship that our gaze establishes with such images is comparable to that which I might experience on contemplating a painting or other work of art. I admire the plastic representation of the subjects, the well-balanced composition, and the powerful contrasts. The aestheticizing trap captures me in a space of dual passivity, ${ }^{80}$ reinforcing subtle hierarchies of looking, and functioning to differentiate between those who have gained the right to see and those who 
are seen, framed and subjected to surveillance. ${ }^{81}$ When looking at this photograph, we at least run the risk of being transformed into passive consumers of images and events.

\section{Conclusion}

In this article, I have examined the relationship between photography and migrations from a cultural geography perspective. In particular, I have focused on the theoretical, epistemological and methodological challenges that a geographical reading of photography poses to traditional visual analyses. Drawing together both the geographical debate on photography and theoretical perspectives from visual culture studies, I first argued for the need to reconceptualise photographs as visual events of place, in which images, spectators and spaces inevitably relate to one another in diverse and fluctuating ways. Echoing Cindy Katz, I termed this critical analysis of the material and social aspects of multiply situated visual events 'a topography of looking'. In the second part of the article, I further developed my line of argument by discussing the role of photography in the discursive construction of the Mediterranean border regime. Finally, I offered a topographical analysis of two particular photographs and some of the performances associated with their production and reception, with a view to illustrating how aesthetic codes, power regimes and emotional responses can interact in practice. Through my examination of photographs taken by Francesco Malavolta and Francesco Zizola during rescue operations in the Central Mediterranean, I attempted to map out some of the potential risks associated with specific aesthetic practices, investigating how the latter can work to foster (and at times to hinder) affective connectedness and political engagement. Rather than providing answers, or solutions to the issues involved in framing migrations, I have preferred throughout the article to draw on my own experience as a viewer in raising a set of critical questions that any viewer should reflexively take into account: What kind of emotional responses do we perform in front of these photographs? Can a sympathetic response open up spaces for agency and engagement? How do we negotiate the affective and political distance between us and the events portrayed? Does a symbolic aesthetics have depoliticizing effects? How can we possibly resist emotional structures that turn us into passive and complicit spectators?

My argument here is that an epistemological inversion in our ways of conceptualizing the relationship between image and viewer is required. The photographic surface is not only an object of inquiry as traditional visual analyses suggest, but can also become a powerful source of reflexive questioning of our own (as viewers, academics or researchers) practices of looking. As a way of approaching not just the image but more importantly our own attitude towards it, this 'looking inward' begins with the ongoing intimate process of asking ourselves: How do I react to this photograph? Mapping out the answers to this fundamental question and how they may be related to broader geopolitical imaginations represents a first step towards grasping the shifting significance of visual representations and performances. By connecting different places and actors (such as photographers, editors, commissioning institutions and spectators) and tracing their mutual relations, the topographic approach discussed here acknowledges photography's multidimensional complexity, shedding fresh light on the trans-scalar events of its happening.

In the book evoked in the title of this article, Susan Sontag discusses Three Guineas by Virginia Woolf, writing that "No "we" should be taken for granted when the subject is looking at other people's pain'. ${ }^{82}$ Any discussion about images of war - she argued - must inevitably question the 'we' at whom such pictures are targeted. Sontag's troubling reflections resonate strongly with my line of reflection throughout this article, especially with regard to migration photography. If the contemporary spectacle of migration is to cease playing out on a silent and unproductive stage of pity and compassion, it is crucial for us to constantly interrogate our own places and performances of looking. If we wish to take on the ethical and political challenges raised by certain photographs of 
migration, we must be prepared to engage in critical and detailed reflection on our own position with respect to racialized topographies and their differential contour lines. Now more than ever, if we are willing to adopt such a reflexive approach, we may aspire to transforming migration photography into a key space for political engagement and cultural criticism.

\section{Funding}

The author(s) received no financial support for the research, authorship, and/or publication of this article.

\section{ORCID iD}

Chiara Giubilaro (iD) https://orcid.org/0000-0001-9197-3577

\section{Notes}

1. See $<$ https://correspondent.afp.com/war-peace $>$ (9 February 2017).

2. See, in this regard, P.Cuttitta, Lo Spettacolo del Confine. Lampedusa tra Produzione e Messa in Scena della Frontiera (Milano: Mimesis, 2012); P.Cuttitta, "Borderizing” the Island Setting and Narratives of the Lampedusa "Border Play"', ACME: An International Journal for Critical Geographies, 13(2), 2014, pp. 196-219; N.De Genova, "Spectacles of Migrant "Illegality": The Scene of Exclusion, the Obscene of Inclusion', Ethnic and Racial Studies, 36(7), 2014, pp. 1180-98.

3. A.Mountz and J.M.Loyd, 'Constructing the Mediterranean Region: Obscuring Violence in the Bordering of Europe's Migration "Crises", ACME: An International Journal for Critical Geographies, 13(2), 2014, pp. 173-95.

4. For a pivotal reflection on the 'spectacle' as a complex social relationship that actively produces and differentiates its viewers, see G.Debord, The Society of the Spectacle (New York: Zone Books, 1994).

5. C.Katz, 'On the Grounds of Globalization: A Topography for Feminist Political Engagement', Signs, 26(4), 2001, pp. 1228-30.

6. Looking, seeing, and gaze are intersecting concepts. Drawing on the work of Shawn Michelle Smith, I use the term looking to denote the social performance of sight, seeing to indicate the conscious perception of it, and gaze to highlight the power structures underlying visual performance: S.M.Smith, 'Guest Editor's Introduction: Visual Culture and Race', MELUS: Multi-Ethnic Literature of the United States, 39(2), 2014, pp. 1-11.

7. See especially N.Genova, 'Spectacles of Migrant "Illegality"'; C.Brambilla, Borderscaping: Imaginations and Practices of Border Making (London and New York: Routledge, 2016).

8. G.R.Kress and T.van Leeuwen, Reading Images: The Grammar of Visual Design (London and New York: Routledge, 1996).

9. D.Massey, For Space (London: SAGE, 2005), pp. 138-39.

10. R.King and N.Wood (eds), Media and Migration: Constructions of Mobility and Difference (London and New York: Routledge, 2001), pp. 10-14.

11. Over the past 3 years, I have interviewed 16 professional photographers, some freelance and some inhouse, working at Europe's southern borders. Their differentiated voices have made, and continue to make, a valuable contribution to my research practice and theoretical inquiry.

12. W.J.T.Mitchell, What Do Pictures Want? (Chicago: The University of Chicago Press, 2005); M.Bal, 'Visual Essentialism and the Object of Visual Culture', Journal of Visual Culture, 5(1), 2006, pp. 53-79; H.Bredekamp, Theorie des Bildakts (Frankfurt: Suhrkamp Verlag, 2011).

13. For a historical account of the relationship between photography and geography, see J.M.Schwartz, 'The Geography Lesson: Photographs and the Construction of Imaginative Geographies', Journal of Historical Geography, 22(1), 1996, pp. 16-45.

14. See, for example, G.Rose, 'Engendering the Slum: Photography in East London in the 1930s', Gender, Place \& Culture, 4(3), 1997, pp. 277-300; G.Rose, 'Visual Culture, Photography and the Urban: An Interpretive Framework', Space and Culture, 2(3), 2014, pp. 4-13; G.Rose, 'Practising Photography: An Archive, a Study, Some Photographs and a Researcher', Journal of Historical Geography, 26(4), 2000, pp. 555-71; J.Schwartz and J.Ryan (eds), Picturing Place: Photography and the Geographical 
Imagination (London: I. B. Tauris, 2006); K.Brickell, 'Home Interiors, National Identity and Curatorial Practice in the Art Photography of Simryn Gill', cultural geographies, 21(3), 2014, pp. 525-32; T.Heng, 'A Wedding Photographer's Journey Through the Chinese Singaporean Urban Landscape', cultural geographies, 19(2), 2012, pp. 259-70; A.Vasudevan, 'The Photographer of Modern Life: Jeff Wall's Photographic Materialism', cultural geographies, 14(4), 2007, pp. 563-88; P.Kinsman, 'Landscape, Race and National Identity: The Photography of Ingrid Pollard', Area, 27(4), 1995, pp. 300-10; C.Withers, 'Picturing Highland Landscapes: George Washington Wilson and the Photography of the Scottish Highlands', Landscape Research, 19(2), 1994, pp. 68-79.

15. P.C.Adams, 'Geographies of Media and Communication I: Metaphysics of Encounter', Progress in Human Geography, 41(3), 2017, pp. 365-74.

16. P.C.Adams, 'Geographies of Media and Communication I', p. 4.

17. G.Rose, 'Engendering the Slum', p. 277.

18. G.Rose, 'On the Need to Ask How, Exactly, Is Geography "Visual”?', Antipode, 35(2), 2003, pp. 212-21.

19. E.Roberts, 'Geography and the Visual Image: A Hauntological Approach', Progress in Human Geography, 37(3), 2012, pp. 386-402.

20. S.Sontag, On Photography (New York: St. Martin's Press, 1977), p. 8.

21. D.Massey, For Space, pp. 138-42.

22. I am referring here to the tragic images of Alan Kurdi taken by Nilufer Demir, and their digital journeys, as described in The Iconic Image on Social Media: A Rapid Research Response to the Death of Aylan Kurdi (Sheffield: Visual Social Media Lab, 2015).

23. See, in this respect, M.S.Ball and G.W.H.Smith, Analyzing Visual Data (London: SAGE, 1992); G.Rose, Visual Methodologies: An Introduction to the Interpretation of Visual Materials (London, SAGE, 2005); M.Crang, 'Visual Methods and Methodologies', in D.DeLyse (ed.), The SAGE Handbook of Qualitative Geography (New York: SAGE, 2010), pp. 208-25.

24. For a critique of universal spectatorship and the so-called 'gaze from nowhere' from a feminist perspective, see D.J.Haraway, 'Situated Knowledges: The Science Question in Feminism and the Privilege of Partial Perspective', Feminist Studies, 14(3), 1988, pp. 575-99; L.Mulvey, 'Visual Pleasure and Narrative Cinema', Screen, 16(3), 1975, pp. 6-18; I.Rogoff, Terra Infirma: Geography's Visual Culture (London and New York: Routledge, 2013).

25. G.Rose, 'Practising photography', p. 567.

26. G.Rose, Visual Methodologies, p. 67.

27. The term 'visual economy' was coined by D.Poole in her Vision, Race, and Modernity: A Visual Economy of the Andean Image World (Princeton: Princeton University Press, 1997).

28. R.Barthes, Camera Lucida: Reflections on Photography (New York: Farrar, Straus and Giroux, 2010), p. 12.

29. E.Edwards, 'Negotiating Spaces: Some Photographic Incidents in the Western Pacific, 1883-84', in J.M.Schwartz and J.R.Ryan (eds), Picturing Place: Photography and the Geographical Imagination (London: I. B. Tauris, 2003), pp. 261-79.

30. For a current overview of cultural readings of media and migrations, see for example: S.Ponzanesi and D.Merolla (eds), Migrant Cartographies: New Cultural and Literary Spaces in Post-Colonial Europe (Lanham: Lexington Books, 2005); T.J.Demos, The Migrant Image: The Art and Politics of Documentary During Global Crisis (Durham and London: Duke University Press, 2013); S.P.Moslund, A.Ring Petersen and M.Schramm (eds), The Culture of Migration: Politics, Aesthetics and Histories (London and New York: I. B. Tauris, 2015); R.King and N.Wood (eds), Media and Migration.

31. For an overview of content analyses as applied to migration photography see P.Gale, 'The Refugee Crisis and Fear: Populist Politics and Media Discourse', Journal of Sociology, 40(4), 2004, pp. 321-40; F.Falk, 'Invasion, Infection, Invisibility: An Iconology of Illegalized Immigration', in C.Bischoff, F.Falk and S.Kafehsy (eds), Images of Illegalized Immigration: Towards a Critical Iconology of Politics (Bielefeld: Transcript, 2010), pp. 83-100; C.Gilligan and C.Marley, 'Migration and Divisions: Thoughts on (Anti-) Narrativity in Visual Representations of Mobile People', Forum: Qualitative Social Research, 11(2), 2010, $<$ http://www.qualitative-research.net/index.php/fqs/article/view/1476>; A.Batziou, "Framing "Otherness" in Press Photographs: The Case of Immigrants in Greece and Spain', Journal of Media Practice, 12(1), 2011, pp. 41-60; C.Lenette and N.Miskovic, “'Some Viewers May Find the Following Images Disturbing”: Visual Representations of Refugee Deaths at Border Crossings', Crime, Media, Culture, 14(1), 2018, pp. 111-20. 
32. A good example of this is R.Bleiker et al., 'The Visual Dehumanisation of Refugees', Australian Journal of Political Science, 48(4), 2013, pp. 398-416.

33. M.Bal, 'Double Movement', in M.Bal and M.Hernandez-Navarro (eds), 2Move: Video Art Migration (Murcia: Cendeac, 2008), pp. 150-61.

34. K.Moxey, 'Visual Studies and the Iconic Turn', Journal of Visual Culture, 7(2), 2008, pp. 131-46.

35. W.J.T.Mitchell, What Do Pictures Want?

36. H.Bredekamp, Theorie des Bildakts.

37. J.Crary, Techniques of the Observer: On Vision and Modernity in the Nineteenth Century (Cambridge: MIT Press, 1990), p. 5. See also J.Crary, Suspensions of Perception: Attention, Spectacle, and Modern Culture (Cambridge, MIT Press, 1999).

38. R.Barthes, Camera Lucida.

39. S.Sontag, On Photography.

40. J.Berger, The Look of Things (New York: The Viking Press, 1971).

41. R.Barthes, Camera Lucida, p. 13.

42. The entanglements between vision and power have also been explored from a popular geopolitics perspective, leading scholars to suggest that the visual media do not just mirror geopolitical issues, but actively contribute to the renegotiation of geopolitical imaginations and practices. See, for example, D.Campbell, 'Geopolitics and Visuality: Sighting the Darfur Conflict', Political Geography, 26(4), 2007, pp. 357-82; F.MacDonald, R.Hughes and K.J.Dodds (eds), Observant States: Geopolitics and Visual Culture (London: I. B. Tauris, 2010); R.Hughes, 'Through the Looking Blast: Geopolitics and Visual Culture', Geography Compass, 1(5), 2007, pp. 976-94; D.Gregory, 'Seeing Red: Baghdad and the Event-Ful City', Political Geography, 29(5), 2010, pp. 266-79.

43. S.Hall, 'The After-Life of Frantz Fanon: Why Fanon? Why Now? Why Black Skin, White Masks?', in A.Read (ed.), The Fact of Blackness (Seattle: Bay Press, 1996), p. 20.

44. T.Jazeel and N.Mookherjee, 'Aesthetics, Politics, Conflict', Journal of Material Culture, 20(4), 2015, pp. 353-60.

45. F.Fanon, Black Skin, White Masks (New York: Grove Press, 2008), p. 84.

46. Bell Hooks, 'Representing Whiteness in the Black Imagination', in L.Grossberg, C.Nelson and B.Treicher (eds), Cultural Studies (London and New York: Routledge, 1992), pp. 338-46.

47. M.Diawara, 'Black Spectatorship: Problems of Identification and Resistance', Screen, 29(4), 1988, pp. 66-79.

48. H.Bhabha, The Location of Culture (London and New York: Routledge, 1994), pp. 66-84.

49. S.M.Smith, 'Guest Editor's Introduction: Visual Culture and Race', p. 2.

50. S.Ahmed, The Cultural Politics of Emotion (New York: Routledge, 2004), p. 10.

51. See, in this regard, L.Boltanski, Distant Suffering: Morality, Media and Politics (Cambridge: Cambridge University Press, 2004); L.Chouliaraki, The Spectatorship of Suffering (London: SAGE, 2006); E.Dauphinée, 'The Politics of the Body in Pain: Reading the Ethics of Imagery', Security Dialogue, 38(2), 2007, pp. 139-55; L.Gross, J.S.Katz and J.Ruby (eds), Image Ethics: The Moral Rights of Subjects in Photographs, Film and Television (Oxford: Oxford University Press, 1988).

52. N.De Genova (ed.), The Borders of 'Europe': Autonomy of Migration, Tactics of Bordering (Durham: Duke University Press, 2017); P.Musarò, 'Mare Nostrum: The Visual Politics of a Military-Humanitarian Operation in the Mediterranean Sea', Media, Culture \& Society, 39(1), 2017, pp. 11-28; E.Balibar, 'In War', OpenDemocracy, 16 November 2015, < https://www.opendemocracy.net/can-europe-make-it/ etienne-balibar/in-war>.

53. A.Mbembe, 'Necropolitics', Public Culture, 15(1), 2003, pp. 11-40.

54. R.Wodak and M.Meyer (eds), Methods for Critical Discourse Analysis (London, SAGE, 2009); G.Rose, Visual Methodologies (London: SAGE, 2001).

55. See <https://frontex.europa.eu/media-centre/photos/joint-operation-triton-2015-1AbBUx> April 2017).

56. I interviewed Francesco Malavolta three times between May 2015 and December 2017, focusing on how his assignments for Frontex materially interfere with his activities as a photojournalist.

57. For further considerations about embedded reporting see J.Butler, Frames of War: When Is Life Grievable? (London and New York: Verso, 2009), pp. 63-6. 
58. Interview with Francesco Malavolta (Palermo, 16 May 2016).

59. Interview with Francesco Malavolta (Palermo, 16 May 2016).

60. Interview with Francesco Malavolta (Palermo, 16 May 2016).

61. Interview with Francesco Malavolta (Palermo, 5 December 2017).

62. See $<$ https://frontex.europa.eu/media-centre/photos/joint-operation-triton-2015-1AbBUx $>$ (28 April 2017).

63. N.De Genova, 'Spectacles of Migrant "Illegality"'.

64. P.Cuttitta, "Borderizing" the Island Setting and Narratives of the Lampedusa "Border Play"'.

65. On the visual stereotype of the female refugee and its depoliticizing effects, see H.L.Johnson, 'Click to Donate: Visual Images, Constructing Victims and Imagining the Female Refugee', Third World Quarterly, 32(6), 2011, pp. 1015-37; L.Chouliaraki and T.Stolic, 'Rethinking Media Responsibility in the Refugee "Crisis": A Visual Typology of European News', Media, Culture \& Society, 39(8), 2017, pp. 1162-77; H.Friese, 'Representations of Gendered Mobility and the Tragic Border Regime in the Mediterranean', Journal of Balkan and Near Eastern Studies, 19(5), 2017, pp. 541-56.

66. N.De Genova, 'Spectacles of Migrant "Illegality".

67. D.Lisle, 'The Surprising Detritus of Leisure: Encountering the Late Photography of War', Environment and Planning D: Society and Space, 29(5), 2011, pp. 873-90.

68. E.Dauphinée, 'The Politics of the Body in Pain'.

69. S.Perera, 'Torturous Dialogues: Geographies of Trauma and Spaces of Exception', Continuum: Journal of Media \& Cultural Studies, 24(1), 2010, pp. 31-45.

70. S.Sontag, Regarding the Pain of Others (New York: Farrar, Straus and Giroux, 2003), p. 102.

71. See $<$ https://www.msf.org/msf-calls-large-scale-search-and-rescue-operation-mediterranean $>$.

72. See $<$ https://www.msf.org.uk/sites/uk/files/ethics_photographers_200809231432.pdf $>$.

73. The photo series may be viewed on the NOOR collective's website: $<$ https://archive.noorimages.com /?10511533054221535940\&EVENT=WEBSHOP_SEARCH\&SEARCHMODE=SERIES\&SHOW SERIES $=1.1127>(26$ August 2015); the video has been published on the website of Italian weekly magazine Internazionale: <https://www.internazionale.it/video/2016/06/01/sulla-stessa-barca-zizola> (1 June 2016).

74. See $<$ https://www.fpmagazine.eu/ita/postcast/Francesco_Zizola_In_the_same_Boat-3/?fbclid=IwAR0 dDBto1Kve-BiO_3KfOzOz-Z-j3VnAhmmVJZ-96x6UT74sJhkxuADnhz8>.

75. See $<$ https://www.nikonschool.it/sguardi/53/zizola.php $>$ (July 2007).

76. See $<$ https://www.nikonschool.it/sguardi/53/zizola.php $>$ (July 2007).

77. S.Hoelscher, 'Photography', in P.C.Adams, J.Craime and J.Dittmer (eds), The Ashgate Research Companion to Media Geography (Farnham and Burlington: Ashgate, 2014), pp. 18-23.

78. On the risk of de-historicization in visual representations, see also J.Berger, The Look of Things; T.Wright, 'Moving Images: The Media Representation of Refugees', Visual Studies, 17(1), 2002, pp. 53-66; L.Malkki, 'Speechless Emissaries: Refugees, Humanitarianism, and Dehistoricization', Cultural Anthropology, 11(3), 2010, pp. 377-404.

79. D.Shields, War Is Beautiful: The New York Times Pictorial Guide to the Glamour of Armed Conflict (New York: PowerHouse Books, 2015); J.Kilby, 'The Visual Fix: The Seductive Beauty of Images of Violence', European Journal of Social Theory, 16(3), 2013, pp. 326-41.

80. S.Sontag, On Photography.

81. S.Hall, 'The Spectacle of the "Other", in S.Hall (ed.), Representation: Cultural Representations and Signifying Processes (London: SAGE, 1997), pp. 223-79.

82. S.Sontag, Regarding the Pain of Others, p. 13.

\section{Author biography}

Chiara Giubilaro was a Research Fellow in Cultural Geography at the University of Milano-Bicocca at the time of writing. She is currently working on mobilities and migrations in the Mediterranean area, focusing on the politics of representation and its normative effects. Her research interests include aesthetics and politics of migrations, urban segregation and socio-spatial justice, geographies of mobility, and philosophical theories of space. 